\title{
培养小学生数学自学解决问题的能力培养探讨
}

\author{
吴兴攀 \\ 六盘水市钟山区大河镇大河小学 \\ D O ::10.32629/jief.v2i1.457
}

[摘 要] 在数学的教学领域中, 如何在对学生传授知识的情况下, 开发学生的自主学习的思维能力, 是当下所有数学教师的研究的重点课题。 思维能力涉及到很多方面，其中培养学生的自学解决问题的能力，对数学教学有着重要的影响。如果一个学生的自学能力得到了提高，那么 他的学习效率也会有明显的增强。所以，培养小学生数学自学解决问题能力是势在必行的，不仅对教师教学有帮助，还对学生的学习成绩有 帮助。

[关键词］小学生数学 ; 自学解决问题 ; 能力培养

自学能力是指学生能够独立的获取知识, 学会运用所学的知识解决 问题。解决问题是数学学习的核心内容, 对学生自学解决问题能力的培养, 是为了让学生能够更好的掌握数学知识, 将知识点都吃透。数学教师对小 学生数学自学解决问题的能力培养, 主要是根据小学生对基础知识的掌握 情况和接受知识的能力来开展教学引导工作, 使学生在学习过程中能够学 会独立思考。通过这种教学方式, 能够使教学过程更加具有灵活性, 调动 学生的思维, 提高学生的学习能力。打破了传统的教学方式的局限性, 使 数学教学水平得到提升。

1 小学数学课堂教学存在的主要问题

1.1 学生对数学学习缺少积极性

由于大多数数学教师在小学课堂教学中, 只注重学生的知识水平是 否得到了提升, 忽略了培养学生的实践能力和创造能力。课堂教学内容过 于枯燥, 教师没有起到很好的引导作用, 只是一味的传授课本内容, 学生 机械化的进行学习, 使学生对教学内容不感兴趣, 没有主动参与的意识, 缺乏学习的主动性, 这样不仅不利于提高数学课堂教学效果, 更会影响学 生的数学成绩。

1.2 教师的教学方法使用不当

自主学习是小学数学课堂学习中最常见的一种教学形式, 在教学过 程中, 几乎每一位数学教师都会设计这种环节, 但是往往因为使用方法不 当而起不到任何效果 ${ }^{[1]}$ 。有的教师一提出问题, 就马上让学生进行自主讨 论, 没有进行详细的讲解, 使有些学生不知道具体要做些什么, 无法提高 教学质量。还有的教师设计的讨论环节过多, 这样反而削弱了教师和学生 之间信息的交流和反馈。

1.3 数学教学内容的缺失

在小学数学教学中, 教师往往只是将课本上的内容单纯的传授给学 生, 但是教材的知识点只是数学教学的辅助素材, 并不能真正让学生领悟 其中的知识点的运用规律。目前还有大多数数学教师认为, 数学教学怎么 教都可以, 存在随意性, 认为教学内容只要丰富就好。这种教育观念, 导 致许多教材内容与生活实际相差甚远, 使学生无法对所讲述的内容知识产 生学习兴趣。

2 培养小学生数学自学解决问题能力的具体方法

2.1 教师要树立正确的教学观念

教师在小学数学教学中要树立正确的教学观念, 摒弃传统的教学 理念, 不断开拓创新。主动进行学习, 多与其他老师进行沟通交流, 学习大家的课堂教学经验, 取长补短、共同进步。要多从学生的实际 情况进行考虑, 及时进行教学方案的创新, 使教学目标和方案符合学 生的素质发展。在教学的过程中, 教师要培养学生的学习能力, 让学 生成为课堂的主体。多给学生课堂参与和发言的机会, 从而调动学生 对学习的积极性。

2.2 激发学生思维, 加强数学应用意识

在小学数学教学课堂中, 教师如果给学生讲述的内容过于抽象, 与 学生的生活没有太大的联系的话, 学生就会觉得无趣, 提不起对学习的热 情和兴趣。相反, 如果教师能够在课堂上提供一些有趣的关于数学的话题 内容, 就会引起学生的兴趣, 吸引学生的注意力。引导学生将所学的知识 运用到实际生活中, 去解决生活中的数学问题。比如, 在对学生讲解 “乘
法和除法计算” 时, 在数学的教材上, 给出了一幅购物的图片, 在货架上 摆放着笔记本，铅笔盒、玩具等等，画面上还有售货员和一个小朋友的对 话。在进行讲解之前, 教师可以为学生创设一个购物的场景, 让学生主动 去商店了解商品信息。向学生提出疑问, 售货员和小朋友在谈论什么? 小 朋友想买多少? 怎么计算到底花了多少钱? 让学生进行自主讨论, 相互交 流, 得出一个属于自己的答案。然后教师再根据学生的回答, 进行详细讲 解。通过开展这种教学模式, 来提高学生的学习热情, 从而培养学生自学 解决问题的能力, 调动学生学习数学的积极性, 营造良好的学习氛围, 使 数学课堂教学变得鲜活生动 ${ }^{[2]}$ 。

2.3 建立自主合作的学习方式

在数学课堂教学中, 教师应该根据学生自身的特点和差异性, 制定 适合每一个学生的教学方案。提倡学生进行自主、合作的学习模式, 让学 生进行独立思考和探究, 成为课堂中的主体。在小组合作学习时, 教师可 以给每个小组指派任务, 让学生合作来完成, 这样可以使学生的课堂参与 度和积极性提高, 也增强了学生的团队意识, 有利于学生间的沟通和交流, 在愉快的氛围中学习到知识。在讲解 “面积的变化” 知识点时, 在完成动 手实验后, 教师为学生创设问题情境, 长方形的长和宽分别扩大了 2 倍, 所以面积也就扩大了两倍。然后让学生根据这个问题进行自主合作讨论学 习, 分析这句话是否正确。学生通过画图, 计算出原来长方形的面积, 再 计算出扩大后的面积, 然后进行对比, 验证了这句话是不正确的。通过这 种自主合作探究的教学方式, 能培养学生自主实践能力, 使学生形成良好 的数学思维模式, 有利于提高数学教学质量。

3 要对学生进行合理的引导教学

要想将自主探究教学的方式运用到小学数学课堂中, 首先老师要注 重课堂上的提问, 对每一个问题的提问都要具有针对性。比如, 在学习 “平 行四边形面积” 时, 教师可以用地砖铺地面的现象作为例子来创设教学情 境, 然后让学生运用所学的知识计算出正方形地砖的面积, 然后再算出需 要的地砖块数。在这个基础之上, 教师对学生进行引导, 如果地砖是平行 四边形的话, 应该需要多少块? 让学生进行自主思考。通过这样的方式能 够加深学生对于该知识点的理解, 让学生明白要求出需要多少块砖, 就先 要求出平行四边形的面积 ${ }^{[3]}$

\section{4 结束语}

由此可见培养小学生自学解决问题的能力不仅能够帮助学生掌握好 知识和学习方法, 还能够提高数学教学质量。将自主探究的教学模式应用 在小学数学中, 能够提高学生分析问题和解决问题的能力, 促进学生综合 能力的提升。

\section{[参考文献]}

[1]梁佑英.小学数学“问题解决”教学策略实施 [J].科技 风,2020(07):61.

[2] 蔡丽萍. 问题导学让深度学习真正发生 [J]. 名师在 线,2020(07):10- 11

[3]毛梦雪,陈文胜.小学生数学合情推理能力培养的教学策略 [J].内蒙 古师范大学学报(教育科学版),2020,33(01):117- 119.

作者简介: 吴兴攀 (1983)，男，贵州盘县人，大专，一级教师 (小), 长期从事在小学数学教学中培养学生自学能力的研究。 